\title{
Isolation of a novel lectin from the dorsal spines of the devil stinger, Inimicus japonicus
}

\author{
Hideyuki Nakagawa $\cdot$ Kuniko Nagasaka $\cdot$ Hitomi Sakai $\cdot$ \\ Kozue Edo $\cdot$ Mitsuko Shinohara $\cdot$ Kiyoshi Ohura
}

Received: 26 January 2015/Accepted: 23 March 2015/Published online: 22 April 2015

(C) The Author(s) 2015. This article is published with open access at Springerlink.com

\begin{abstract}
A novel lectin was purified from the dorsal spines of the devil stinger, Inimicus japonicus using a combination of affinity chromatography techniques. A single band was detected on a native PAGE gel with a relative molecular mass of $97 \mathrm{kDa}$. The N-terminal partial amino acid of the intact $75 \mathrm{kDa}$ subunit of the $97 \mathrm{kDa}$ lectin was found to be DHEDS. The agglutination of rabbit erythrocytes by the $97 \mathrm{kDa}$ lectin was inhibited most effectively by methyl $\alpha$-D-mannoside. The $97 \mathrm{kDa}$ lectin stimulated mitogenesis in murine splenocytes. This is the first study to examine the dorsal lectin of I. japonicus and one of the very few studies on venom lectins from venomous scorpaeniform fish. These results suggest that the devil stinger, I. japonicus, may be a novel resource for biologically active substances.
\end{abstract}

Keywords Devil stinger - Inimicus japonicus - Dorsal spine - Lectin · Agglutination - Mitogenic activity · Murine splenocytes

H. Nakagawa $(\bowtie) \cdot$ H. Sakai

Division of Environmental Symbiosis, Graduate School of Integrated Arts and Sciences, Tokushima University,

Tokushima 770-8502, Japan

e-mail: sea-hide@tokushima-u.ac.jp

H. Sakai

e-mail: sakai.hitomi@tokushima-u.ac.jp

K. Nagasaka

Fukae Nagasaka Clinic, Etajima 737-2214, Japan

e-mail: fkengski@ace.ocn.ne.jp

K. Edo

Junior College Division, Department of Science for Human Health, Shikoku University, Tokushima 771-1192, Japan

e-mail: kozue-edo@shikoku-u.ac.jp

M. Shinohara $\cdot$ K. Ohura

Department of Pharmacology, Osaka Dental University, Hirakata 573-1121, Japan

e-mail: shino.m@gol.com

K. Ohura

e-mail: ohura@cc.osaka-dent.ac.jp 


\section{Background}

A large number of venomous and poisonous animals exist in aquatic environments worldwide. More than 200 of the approximately 22,000 species of fish in the ocean are considered to be venomous (Halstead 1988; Russell 1996). Most of these venomous fish are non-migratory, slow moving, and mainly live in shallow waters in protected habitats (Maretic 1988). Venomous scorpaeniform fish include the lionfish and scorpionfish from the family Scorpaenidae, devil stinger and stonefish from the family Synanceiidae, and waspfish from the family Tetrarogidae (Kiriake et al. 2013). These fish possess 11-17 dorsal, 2 pelvic, and 3 anal spines, with the venom secretory complex being located within the anterolateral grooves of these spines (Russell 1965; Halstead 1988; Haddad et al. 2003; Smith and Wheeler 2006; Andrich et al. 2010).

The devil stinger Inimicus japonicus, which belongs to the family Synanceiidae, has 17 dorsal, 1 pelvic, and 2 anal spines, which contain venom glands that are covered by an integumentary sheath (Tange 1954). I. japonicus, a valuable demersal scorpaenid fish, is widely distributed along the coastal areas of eastern Asia at a depth of between 10 and $200 \mathrm{~m}$ (Wang et al. 2013). The body of Inimicus is covered in warts or skin lumps, with many skin tubercle glands similar to the stonefish. Envenomation occurs when people carelessly handle or step on these fish, and are stung by the dorsal spines. Envenomation appears immediately as intense, sharp, and persisting local pain, and swelling around the sting (Auerbach 1991; Yamamoto et al. 2010). Symptoms depend on the amount of venom injected. Systemic effects including dizziness, fever, and delirium have been reported (Auerbach 1991). However, only a limited number of studies have investigated the toxicity of $I$. japonicus. Therefore, we herein examined the dorsal venom of the devil stinger, I. japonicus using column chromatography and, for the first time, separated a novel lectin that induced mitogenic activity.

\section{Methods}

Isolation of a dorsal lectin

Inimicus japonicus (18 specimens, average size of $20 \mathrm{~cm}$ ) were collected by local fishermen from the coast of Hiroshima Prefecture and Tokushima Prefecture, Japan in May 2003 (Fig. 1a, b). The collected fish were transported alive or frozen to our laboratory. The dorsal spines (a total of 17) of I. japonicus were cut from their base, and the dorsal venom protein was extracted with $0.15 \mathrm{M} \mathrm{NaCl}$ as reported previously (Nagasaka et al. 2009). Briefly, in the first step of purification, the venom protein was applied to a Phenyl Sepharose CL4B (GE Healthcare, Uppsala, Sweden) affinity chromatographic column $(2 \mathrm{ml})$ equilibrated with $16 \mathrm{mM}$ Tris$\mathrm{HCl}$ buffer containing $2 \mathrm{M} \mathrm{NaCl}(\mathrm{pH}$ 7.4). The sample was rinsed and washed with the same buffer containing $0.01 \mathrm{M} \mathrm{NaCl}$ at a flow rate of $20 \mathrm{ml} / \mathrm{h}$ (Fig. 1a). The 2-ml elution fractions were collected and analyzed for absorption at $280 \mathrm{~nm}$ and agglutinating activity. Each of the unbound and bound fractions was pooled and
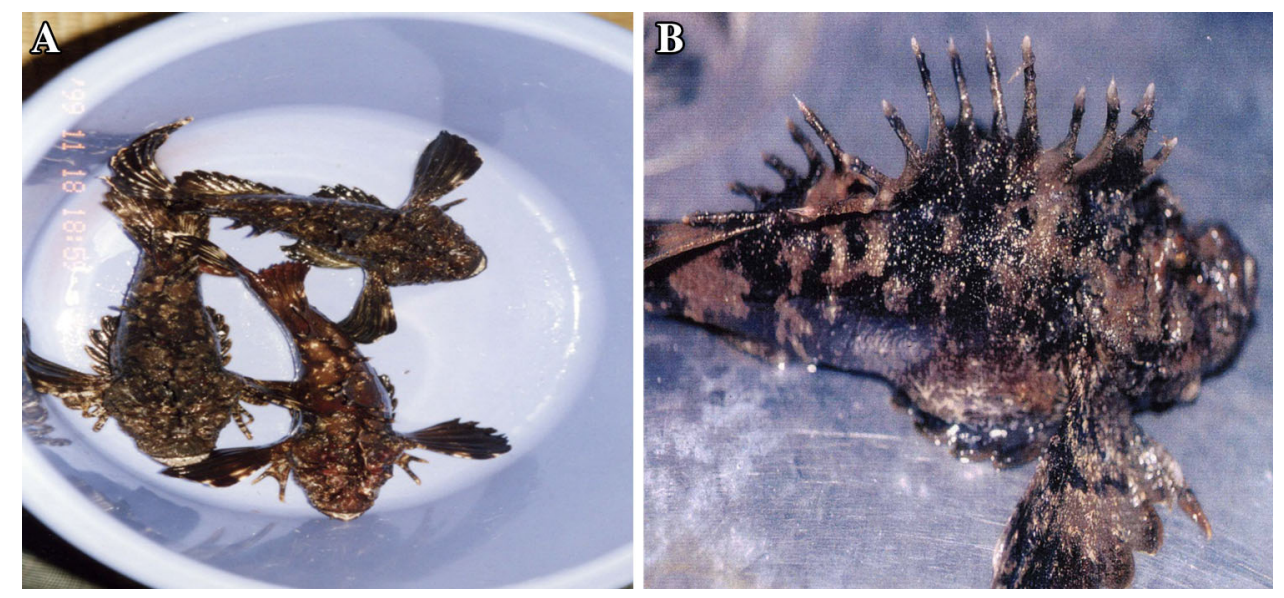

Fig. 1 The devil stinger Inimicus japonicus as seen from above (a) and a specimen with erect dorsal spines (b) 
analyzed for electrophoresis. The final step of purification was achieved using a Concanavalin A-Sepharose 4B (Sigma-Aldrich, Missouri, USA) column $(2 \mathrm{ml})$ equilibrated with $20 \mathrm{mM}$ Tris-HCl buffer containing $0.4 \mathrm{M} \mathrm{NaCl}$ ( $\mathrm{pH} \mathrm{7.4).} \mathrm{The} \mathrm{unbound} \mathrm{fraction} \mathrm{(the} \mathrm{PS-I} \mathrm{fraction)} \mathrm{was} \mathrm{rinsed} \mathrm{and} \mathrm{washed} \mathrm{with} \mathrm{the} \mathrm{same} \mathrm{buffer,}$ and eluted with the same buffer containing $100 \mathrm{mM}$ methyl- $\alpha$-D-mannoside in the buffer at a flow rate of $20 \mathrm{ml} / \mathrm{h}$ (Fig. 1b). Elution fractions $(2 \mathrm{ml})$ were collected and analyzed for absorption at $280 \mathrm{~nm}$ and agglutinating activity. Each of the unbound (PS-I-ConA-I fraction) and bound (PS-I-ConA-II fraction) fractions was pooled and analyzed for electrophoresis. PS-I-ConA-II was then used as the purified lectin. Protein content was measured according to the method of Bradford (1976) using bovine albumin as a standard.

\section{Electrophoresis}

Polyacrylamide gel electrophoresis (PAGE) was performed as described by Davis (1964) using a 4-20\% gradient gel. Sodium dodecyl sulfate (SDS)-PAGE was carried out by the method of Laemmli (1970) using a 10-20\% gradient gel. Protein samples were heated in the presence of 2-mercaptoethanol for 4 min at $98{ }^{\circ} \mathrm{C}$. The gels were stained with Coomassie brilliant blue.

Glycoprotein staining

The glycoprotein sugar moieties of the sample protein were detected in the SDS-PAGE gel using the GelCode Glycoprotein kit (Pierce Biotech., Inc., IL, USA). This kit detects sugars that occur in glycoproteins, including galactose, mannose, glucose, $\mathrm{N}$-acetylglucose, $\mathrm{N}$-acetylgalactosamine, sialic acid, fucose, and xylose.

Assay of agglutinating activity

Agglutinating activity was assayed using rabbit erythrocytes on microtiter plates. Twenty-five microliters of a $2 \%(\mathrm{v} / \mathrm{v})$ suspension of erythrocytes in $6.4 \mathrm{mM}$ phosphate-buffered saline (PBS) was added to $50 \mu \mathrm{l}$ of a serial twofold dilution of the sample. The plates were incubated at room temperature for $1 \mathrm{~h}$. The results obtained were expressed by the minimum concentration of the sample $(\mu \mathrm{g} / \mathrm{ml})$ required for positive agglutination. The inhibition of agglutination was expressed as the minimum concentration of each sugar required to inhibit the agglutinating activity of the sample.

Mitogenic activity

Mitogenic activity in murine splenocytes was determined using a cell culture assay with a dye, the tetrazolium salt 3(4,5-dimethylthiazol-2-yl)-2,5-diphenyltetrazolium bromide (MTT) (Nakagawa et al. 1997). Splenocytes were collected from female ddY mice and suspended in RPMI-1640 medium supplemented with penicillin and streptomycin $(100 \mu \mathrm{g} / \mathrm{ml}$ and $100 \mathrm{U} / \mathrm{ml})$. Splenocytes $\left(5 \times 10^{6}\right.$ cells $\left./ \mathrm{ml}\right)$ with or without concanavalin A $(1 \mu \mathrm{g} / \mathrm{ml})$ and samples were plated on flat-bottom microplates and incubated at $37{ }^{\circ} \mathrm{C}$ in a humidified atmosphere containing $5 \% \mathrm{CO}_{2}$ for $68 \mathrm{~h}$. Ten microliters of the MTT tetrazolium salt solution $(5 \mathrm{mg} / \mathrm{ml}) \mathrm{was}$ then introduced into each well, and formazan was extracted from the cells with $10 \%$ sodium sulfate (SDS) after $4 \mathrm{~h}$. The optical density of each well was measured spectrophotometrically with a microplate reader (Thermo Fisher Scientific, MultiskanGo, Yokohama, Japan) at $570 \mathrm{~nm}$.

N-terminal amino acid sequencing

Approximately, $3 \mu \mathrm{g}$ of the sample protein was subjected to SDS-PGE, followed by electroblotting on a polyvinylidene difluoride membrane. The membrane was then stained with Ponceau $\mathrm{S}$ and destained. The protein band was excised and subjected to automated Edman degradation using the Shimadzu Model PPSQ-30 protein sequencer (Shimadzu Corp., Kyoto, Japan). 
Statistical analysis

Data are expressed as the mean or mean \pm standard deviation (SD). Statistical analyses were performed using the SPSS version 16.0 software package (SPSS, Chicago, Inc., IL, USA). Statistical analyses of the results obtained were performed using Dunnett's multiple comparison test when various experimental groups were compared to the control groups, and the Student's $t$ test was used for paired groups. $P<0.05$ was considered significant.

\section{Results and discussion}

Dorsal venom was previously reported to induce weak agglutination in rabbit erythrocytes and stimulated mitogenesis in murine splenocytes (Nakagawa et al. 2011). The venom possessed a glycoprotein that was stained by SDS-PAGE using the GelCode Glycoprotein kit, indicating that it contained one band corresponding to a protein with an apparent mass of $75 \mathrm{kDa}$ (data not shown). Therefore, we herein attempted to isolate a lectin from the dorsal spines of I. japonicus using a combination of affinity chromatography techniques (Fig. 2a, b). Dorsal venom was applied to a Phenyl Sepharose CL-4B column (2 ml) equilibrated with $16 \mathrm{mM}$ Tris- $\mathrm{HCl}$ buffer containing $2 \mathrm{M} \mathrm{NaCl}$ (pH 7.4). The sample was rinsed with the same buffer and then eluted with the same buffer containing $0.01 \mathrm{M} \mathrm{NaCl}$ at a flow rate of $20 \mathrm{ml} / \mathrm{h}$. Figure 2 a shows the elution pattern with two protein peaks. The first peak (the PS-I fraction) induced agglutinating activity at a dose of $6.25 \mu \mathrm{g} / \mathrm{ml}$, while the second peak (the PS-II fraction) induced this activity at a higher dose of $200 \mu \mathrm{g} / \mathrm{ml}$ (data not shown). SDS-PAGE analysis of the PS-I fraction showed two main bands that corresponded to proteins with apparent masses of 30 and $97 \mathrm{kDa}$ (Fig. 2a). The PS-I fraction was applied to a Concanavalin A-Sepharose 4B column ( $2 \mathrm{ml}$ ) equilibrated with $20 \mathrm{mM}$ Tris- $\mathrm{HCl}$ buffer containing $0.4 \mathrm{M} \mathrm{NaCl}(\mathrm{pH} 7.4)$ for purification. The column was rinsed thoroughly with the same buffer and then eluted with $100 \mathrm{mM}$ methyl- $\alpha-$ D-mannoside in the buffer at a flow rate of $20 \mathrm{ml} / \mathrm{h}$.

As shown in Fig. 2b, a native PAGE analysis of the unbound fraction (the PS-I-ConA-I fraction) identified two bands corresponding to proteins with apparent masses of 30 and $97 \mathrm{kDa}$. On the other hand, the bound fraction (the PS-I-ConA-II fraction) showed a single discrete band corresponding to a protein with an apparent mass of $97 \mathrm{kDa}$. The PS-I-Con A-II fraction was a glycoprotein fraction that contained mannose residues. This glycoprotein fraction was designated as a $97 \mathrm{kDa}$ lectin. The recovery of the $97 \mathrm{kDa}$ lectin in terms of protein content accounted for $0.35 \%$ of the dorsal venom. SDS-PAGE showed that the $97 \mathrm{kDa}$ lectin was mainly composed of 75 and $30 \mathrm{kDa}$ subunits (Fig. 2b). The $75 \mathrm{kDa}$ subunit of the $97 \mathrm{kDa}$ lectin was subjected to a partial amino acid sequence analysis. The N-terminal amino acid of the $75 \mathrm{kDa}$ subunit was aspartic acid. The partial amino acid sequence was determined up to 5 residues, and found to be DHEDS. In the case of the waspfish Hypodytes rubripinnis, Karatoxin, a novel cytotoxic protein $(110 \mathrm{kDa})$, was successfully purified from the dorsal spines of this fish (Nagasaka et al. 2009; Shinohara et al. 2010). The N-terminal partial amino acid sequence of the $76 \mathrm{kDa}$ subunit of Karatoxin was shown to be DQHDDxPxxAPDPG. As the partial amino acid sequence of the $75 \mathrm{kDa}$ subunit of the $97 \mathrm{kDa}$ lectin was only analyzed up to 5 residues, it is currently difficult to determine whether it shares homology with the $76 \mathrm{kDa}$ subunit of Karatoxin. Therefore, we are now attempting to improve the purifying method as well as the recovery of the $97 \mathrm{kDa}$ lectin from the dorsal venom. Kiriake et al. (2013) recently identified the toxin of I. japonicus as a $160 \mathrm{kDa}$ heterodimer composed of $80 \mathrm{kDa} \alpha$ - and $\beta$-subunits by cDNA cloning. This toxin was very similar to those of the lionfish $P$. lunulata and waspfish $H$. rubripinnis. The venoms of most venomous fish have been proposed to have similar toxic properties and molecules with similar structures (Saunders 1960; Russell 1965; Church and Hodgson 2002). Therefore, more detailed studies on the structure of the $97 \mathrm{kDa}$ lectin are needed to elucidate its sequence homology to Karatoxin and piscine venoms such as those from the stonefish.

The agglutinating activity of the $97 \mathrm{kDa}$ lectin was inhibited most effectively by methyl $\alpha$-D-mannoside and, to a lesser extent, by D-mannose, and D-Glucose, suggesting that the hydrogen groups at C-1, C-3, and C-4 of the pyranose ring structure influenced sugar binding to the lectin (Table 1). Figure 3 shows the results of mitogen responses in murine splenocytes in the presence of the dorsal venom and PS-I-ConA fractions (the PS-I-ConA-I fraction and PS-I-ConA-II fraction). As shown in Fig. 3a, the dorsal venom induced mitogenic activity in murine splenocytes at doses ranging from 25 to $50 \mu \mathrm{g} / \mathrm{ml}$. However, a higher dose $(100 \mu \mathrm{g} / \mathrm{ml})$ of 

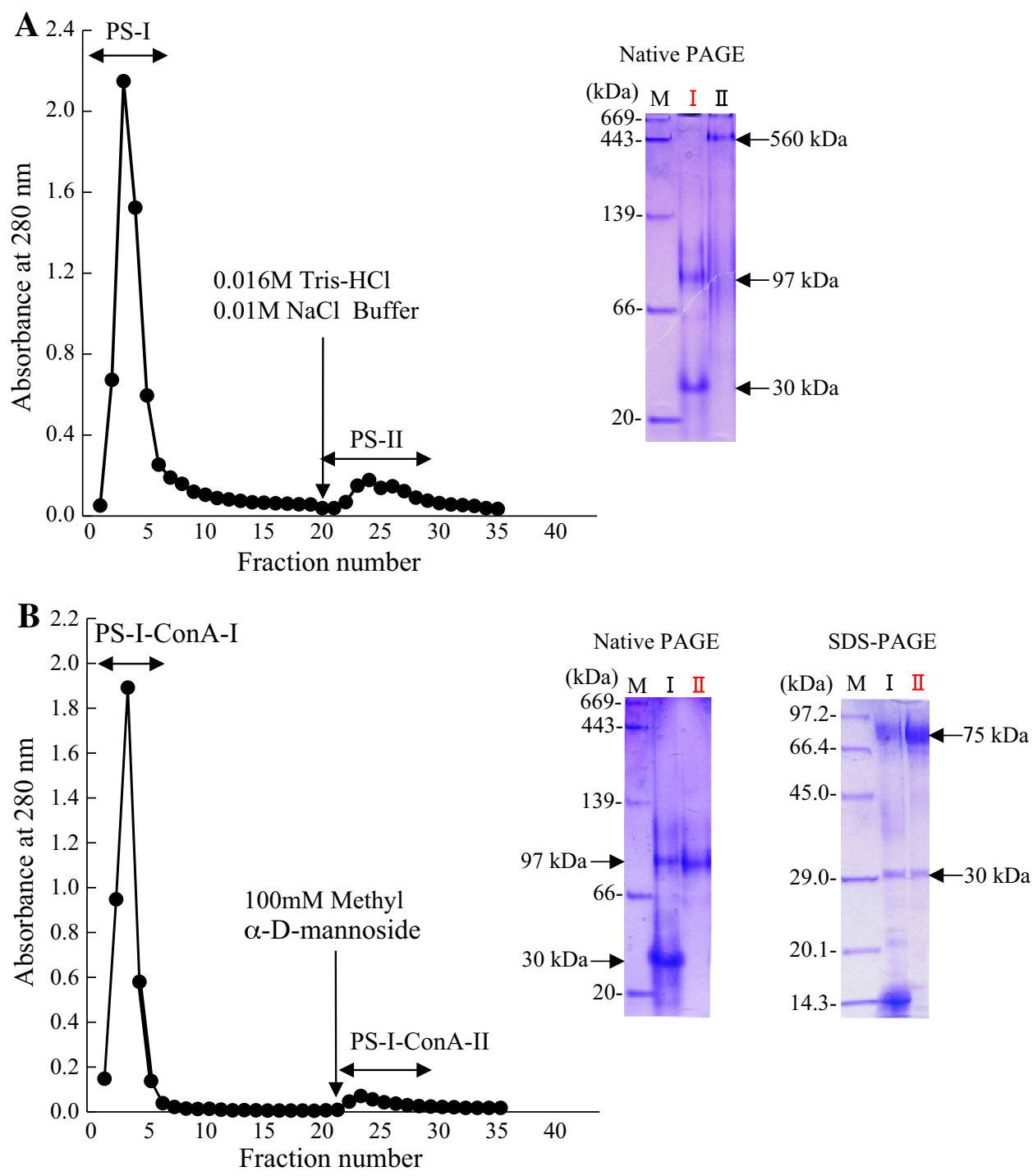

Fig. 2 Isolation of a novel lectin from dorsal spines of Inimicus japonicus. The isolation procedure was described in detail in "Methods". a The first purification step used Phenyl Sepharose CL-4B. b The second purification step used Concanavalin A-Sepharose 4B. Inset panels show native PAGE and SDS-PAGE of affinity chromatographic fractions. $M$ mol wt markers

Table 1 Sugar inhibition of agglutinating activity of $97 \mathrm{kDa}$ lectin

\begin{tabular}{ll}
\hline Sugar & Minimum effective concentration (mM) \\
\hline D-Mannose & 3.1 \\
Methyl a-D-mannoside & 0.78 \\
D-Glucose & 12.5 \\
$N$-Acetylglucosamine & 12.5 \\
Others $^{\mathrm{a}}$ & NI 100 \\
\hline
\end{tabular}

NI non-inhibitory

a D-Galactose, D-Fucose, L-Glucose, D-Galactosamine, Lactose

the dorsal venom significantly decreased mitogenic activity, suggesting the presence of another biologically active component in addition to lectin component(s) in the venom. Most piscine venoms have been shown to exhibit potent cytolytic activity (Shier 1988; Church and Hodgson 2002). We also observed cytotoxic activity in human leukemia cells (K562) by the dorsal venom (unpublished data). The PS-I-ConA-I fraction and 
Fig. 3 Mitogen responses of the dorsal venom (a) and PS-I-ConA fractions (b) in murine splenocytes. Splenocytes $\left(5 \times 10^{6}\right.$ cells $\left./ \mathrm{ml}\right)$ were incubated with the dorsal venom, PS-I-ConA-I and PS-I-ConA-II (97 $\mathrm{kDa}$ lectin), for $68 \mathrm{~h}$ and the incubation was continued with MTT for $4 \mathrm{~h}$ in a $\mathrm{CO}_{2}$ humidified atmosphere. Data show the mean $\pm \mathrm{SD}$ of two experiments performed in triplicate (a) or the mean \pm SD of 3-4 experiments performed in triplicate $(\mathbf{b})$. $* * P<0.01$, significantly different from the negative control. ${ }^{\#} P<0.05,{ }^{\# \#} P<0.01$, ${ }^{\# \# \# P<0.001 \text {, significant difference between }}$ two groups according to the Student's unpaired $t$ test
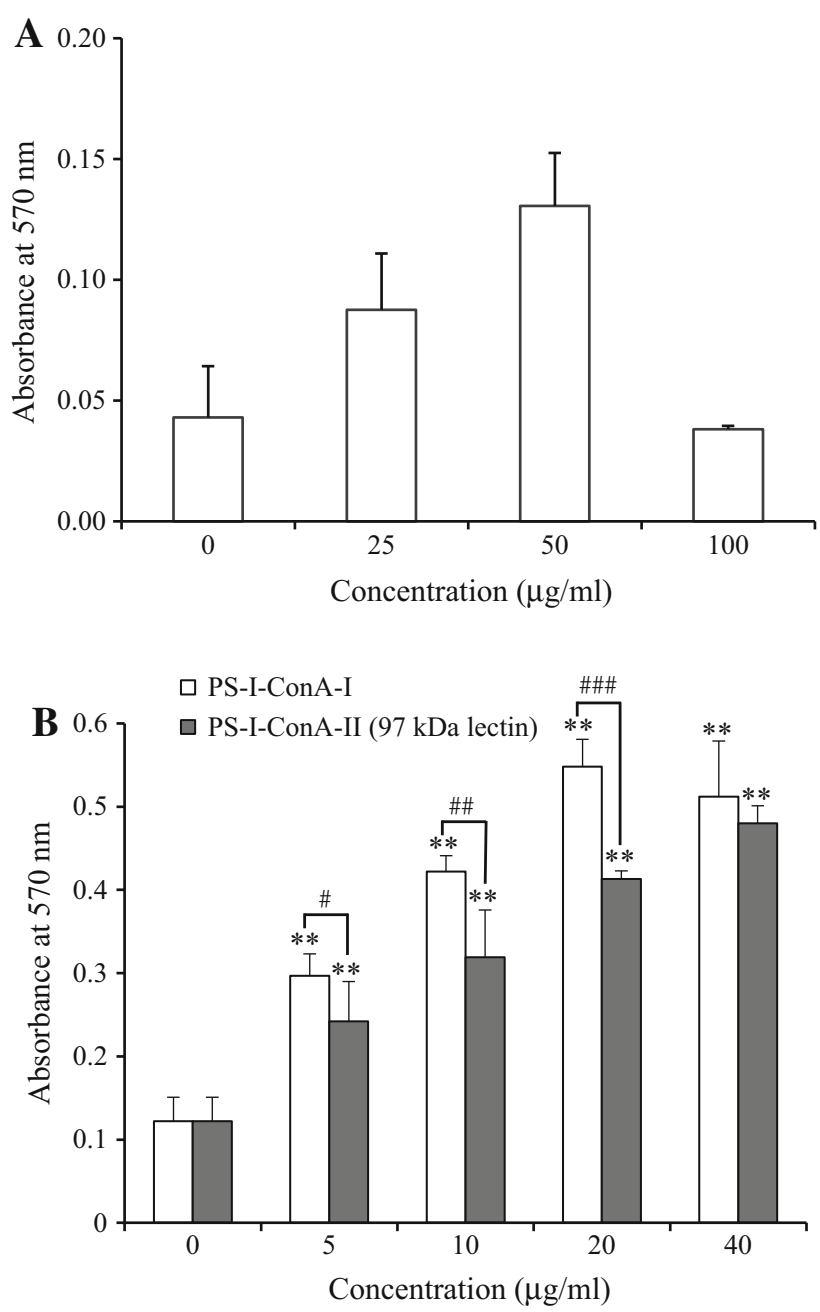

$97 \mathrm{kDa}$ lectin effectively induced mitogenesis in a dose-dependent manner in murine splenocytes (Fig. 3b). The mitogenic activity induced by the PS-I-ConA-I fraction was slightly higher than that induced by the $97 \mathrm{kDa}$ lectin. This suggests that there is a quantitative and/or qualitative difference in the lectin component between the two fractions. Further biological and structural studies on the PS-I-ConA-I fraction may lead to the identification of more novel lectin(s).

Lectins are a large group of proteins that reversibly bind specific carbohydrates and possess at least one non-catalytic domain (Drickamer 1988). Although many lectins have been isolated from various plants, bacteria, and animals, including invertebrates (Drickamer and Taylor 1993; Hatakeyama et al. 1994; Nakagawa et al. 2003; Sharon and Lis 2004; Malagoli et al. 2010), very few have been detected in marine vertebrates, particularly venomous fish (Satoh et al. 2002; Nagasaka et al. 2009). In the present study, we successfully isolated and partially characterized the $97 \mathrm{kDa}$ lectin from I. japonicus as a novel piscine lectin. The $97 \mathrm{kDa}$ lectin from I. japonicus venom exhibited mitogenic activity in murine splenocytes, suggesting that it may contribute to the local and systemic effects observed on envenomation such as swelling, severe pain, and fever. We more recently observed chemotactic activity in guinea-pig neutrophils (unpublished data). Thus, the $97 \mathrm{kDa}$ lectin may affect inflammatory and immunomodulatory processes. The agglutination induced by the $97 \mathrm{kDa}$ lectin was inhibited by D-mannose and methyl $\alpha$-D-mannoside. These results suggest that the $97 \mathrm{kDa}$ lectin may induce mitogenic activity by binding the mannose-containing carbohydrate chains present on the surface of murine splenocytes. Further studies are needed to clarify the mechanisms underlying the biological activities of the $97 \mathrm{kDa}$ lectin. Moreover, an investigation of the structural features of this lectin is needed to elucidate the physiological significance of venom from I. japonicus. The present results suggest 
that the $97 \mathrm{kDa}$ lectin from I. japonicus venom is a source of biologically active substances, which may have applications as research tools.

\section{Conclusions}

A novel lectin was isolated from the dorsal spines of I. japonicus using a combination of affinity chromatography techniques. Native PAGE showed that the dorsal lectin was a glycoprotein with a molecular mass of $97 \mathrm{kDa}$.

The agglutinating activity of the $97 \mathrm{kDa}$ lectin was effectively inhibited by methyl $\alpha$-D-mannoside. The $97 \mathrm{kDa}$ lectin may exhibit mitogenic activity by binding to a specific carbohydrate chain, such as mannose moieties on the cell surface. Our results suggest that the venom of the devil stinger, I. japonicus is a potent resource for piscine lectins.

Author contributions HN prepared the manuscript, and supervised the experiments. KN participated in the experiment design and manuscript writing. HS conducted the purification of dorsal lectin. KE conducted the mitogenic activity and agglutination activity assay. MS participated in the interpretation of the results. KO participated in the study design. All authors read and approved the final manuscript.

Acknowledgments The authors are indebted to Mr. Hidenori Yuasa for collecting the I. japonicus specimens, and Mr. Takefumi Hosotani, Mr. Masashi Miyata, and Ms. Atsumi Harada for their assistance purifying the dorsal venom lectin from the fish.

Conflict of interest The authors declare that they have no competing interests.

Open Access This article is distributed under the terms of the Creative Commons Attribution 4.0 International License (http:// creativecommons.org/licenses/by/4.0/), which permits unrestricted use, distribution, and reproduction in any medium, provided you give appropriate credit to the original author(s) and the source, provide a link to the Creative Commons license, and indicate if changes were made.

\section{References}

Andrich F, Garnielli JBT, Cassoli JS, Lautner RQ, Santos RAS, Pimenta AMC, de Lima ME, Figueiredo SG (2010) A potent vasoactive cytolysin isolated from Scorpaena plumieri scorpionfish venom. Toxicon 56:487-496

Auerbach PS (1991) Marine envenomations. N Engl J Med 325:486-493

Bradford MM (1976) A rapid and sensitive methods for quantitation of microgram quantities of protein utilizing the principle of protein-dye binding. Anal Biochem 72:248-254

Church JE, Hodgson WC (2002) The pharmacological activity of fish venoms. Toxicon 40:1083-1093

Davis BJ (1964) Disc electrophoresis II. Method and application to human serum proteins. Ann NY Acad Sci 121:404-427

Drickamer K (1988) Two distinct classes of carbohydrate-recognition domains in animal lectins. J Biol Chem 263:9557-9560

Drickamer K, Taylor ME (1993) Biology of animal lectins. Annu Rev Cell Biol 9:237-264

Haddad V Jr, Marins IA, Makyama HM (2003) Injuries caused by scopionfishes (Scorpaena plumieri Bloch, 1789 and Scopaena brasiliensis Cuvier, 1829) in the Southwestern Atlantic Ocean (Brazilian coast): epidemiologic, clinic and therapeutic aspects of 23 stings in humans. Toxicon 42:79-83

Halstead BW (1988) Poisonous and venomous marine animals of the world, 2nd edn. Darwin Press, Princeton, pp 1168. (Plates pp 288)

Hatakeyama T, Kohzaki H, Nagatomo H, Yamazaki N (1994) Purification and characterization of four Ca2+-dependent lectins from the marine invertebrate, Cucumaria echinata. J Biochem 116:209-214

Kiriake A, Suzuki Y, Nagashima Y, Shiomi K (2013) Proteinaceous toxins from three species of scorpaeniform fish (lionfish Pterois lunulata, devil stinger Inimicus japonicus and waspfish Hypodytes rubripinnis): close similarity in properties and primary structures to stonefish toxins. Toxicon 70:184-193

Laemmli UK (1970) Cleavage of structural protein during the assembly of the head of the bacteriophage T4. Nature 227:680-685

Malagoli D, Sacchi S, Ottaviani E (2010) Lectins and cytokines in celomatic invertebrates: two tales with the same end. Inv Surv J 7:1-10

Maretic Z (1988) Fish Venom. In: Tu AT (ed) Handbook of natural toxins: marine toxins and venoms, vol 3. Marcel Dekker, New York, pp 445-477

Nagasaka K, Nakagawa H, Satoh F, Hosotani T, Yokoigawa K, Sakai H, Sakuraba H, Ohshima T, Shinohara M, Ohura K (2009) A novel cytotoxic protein, Karatoxin, from the dorsal spines of the redfin velvetfish, Hypodytes rubripinnis. Toxin Rev 28:260-265

Nakagawa H, Yamaguchi C, Hayashi H (1997) Biologically active substances from sea urchins. J Nat Toxins 6:193-202 
Nakagawa H, Tanigawa T, Tomita K, Tomihara Y, Araki Y, Tachikawa E (2003) Recent studies on the pathological effects of purified sea urchin toxins. J Toxicol Toxin Rev 22:633-649

Nakagawa H, Edo K, Sakai H, Watanabe Y, Shinohara M, Ohura K (2011) Mining on novel lectins from some venomous fish and sea urchins. In: Program abstracts of the 9th IST Pacific meeting on animal, plant and microbial toxins. Vladivostok, Suppl: P10

Russell FE (1965) Marine toxins and venomous and poisonous marine animals. In: Russell FE (ed) Advances in marine biology, vol 2. Academic Press, London, pp 137-151

Russell FE (1996) Toxic effects of animal toxins. In: Klassen CD (ed) Casarett and doull's toxicology-the basic science of poisons. McGraw-Hill, Sydney, pp 801-839

Satoh F, Nakagawa H, Yamada H, Nagasaka K, Nagasaka T, Araki Y, Tomihata Y, Nozaki M, Sakuraba H, Ohshima T, Hatakeyama T, Aoyagi H (2002) Fishing for bioactive substances from scorpionfish and some sea urchins. J Nat Toxins 11:297-304

Saunders PR (1960) Pharmacological and chemical studies of the venom of stonefish (Genus Synacceija) and other scorpionfishes. Ann NY Acad Sci 90:789-804

Sharon N, Lis H (2004) History of lectins: from hemagglutinins to biological recognition molecules. Glycobiology 14:53-62

Shier WT (1988) Cytotoxic Effect of Marine Toxins and Venoms. In: Tu AT (ed) Handbook of natural toxins: marine toxins and venoms, vol 3. Marcel Dekker, New York, pp 477-491

Shinohara M, Nagasaka K, Nakagawa H, Edo K, Sakai H, Kato K, Iwaki F, Ohura K, Sakuraba H (2010) A novel chemoattractant lectin, Karatoxin, from the dorsal spines of the small scorpionfish Hypodytes rubripinnis. J Pharmacol Sci 113:414-417

Smith WL, Wheeler WC (2006) Venom evolution widespread in fishes: a phylogenetic road map for the bioprospecting of piscine venoms. J Hered 97:206-217

Tange Y (1954) On the morphology of the poison apparatus in Japanese fish with remarks on its toxicity. VII. The poison apparatus in Inimicus japonicus (Cuvier et Valenciennes). Yokohama Med Bull 5:234-242

Wang Y, Li L, Cui G, Lu W (2013) Ontogenesis from embryo to juvenile and salinity tolerance of Japanese devil stinger Inimicus japonicus during early life stage. Springer Plus 2:289. http://www.sprigerplus.com/content/2/1/289

Yamamoto R, Suzuki M, Hori S, Aikawa N (2010) Stonefish "Okoze" envenomation during food preparation. Keio J Med 59:19-22 